\title{
Inhibition of tetramethylpyrazine on P-gp, MRP2, MRP3 and MRP5 in multidrug resistant human hepatocellular carcinoma cells
}

\author{
XUAN-BIN WANG ${ }^{1,2}$, SHAN-SHAN WANG ${ }^{2}$, QIU-FANG ZHANG ${ }^{1,3}$, MING LIU $^{2}$, HONG-LIANG LI ${ }^{2}$, \\ YING LIU ${ }^{2}$, JIA-NING WANG ${ }^{4}$, FEI ZHENG ${ }^{4}$, LING-YUN GUO ${ }^{4}$ and JI-ZHOU XIANG ${ }^{1}$ \\ ${ }^{1}$ Department of Pharmacology, Tongji Medical College, Huazhong University of Science and Technology, Wuhan \\ 430030; ${ }^{2}$ Laboratory of Chinese Herbal Pharmacology, Renmin Hospital, ${ }^{3}$ Department of Pharmacology, \\ ${ }^{4}$ Institute of Clinical Medicine, Yunyang Medical College, Shiyan 442000, P.R. China
}

Received June 23, 2009; Accepted September 17, 2009

DOI: $10.3892 /$ or_00000625

\begin{abstract}
Some membrane transporters in liver, such as P-glycoprotein, multidrug resistance-associated protein 2 (MRP2), MRP3, and MRP5 can lead to a complex multidrug resistance (MDR) to antineoplastic agents. How to inhibit these proteins is still an issue. Tetramethylpyrazine is a bioactive constituent isolated from the root of Ligusticum chuanxiong Hort, a Chinese herb. Recent studies showed that it can enhance the chemosensitivity effects of a drug on human hepatocellular carcinoma cells, acting as a multidrug resistance modulator. In this study, the reversal effect of TMP on MDR was evaluated and its activity mechanism in vitro was explored. The $\mathrm{IC}_{50}$ value shows that TMP reversed the multidrug resistance of BEL-7402/ADM cells 9.23-fold $(\mathrm{P}<0.01)$ at the concentration of $600 \mu \mathrm{M}$. The mean fluorescence intensity of ADM in BEL-7402/ADM cells with TMP was found to be $163.78 \pm 39.5 \%(\mathrm{P}<0.01)$ versus in BEL-7402/ADM cells without TMP by flow cytometry and $126.73 \pm 28.72 \%$ in BEL-7402/ADM cells with TMP versus in BEL-7402/ADM cells without TMP $(\mathrm{P}<0.01)$ by high performance liquid chromatography, respectively. It was also found that the mRNA level of multidrug resistant gene MDR1, MRP2, MRP3 and MRP5 and the level of the proteins they encode were decreased after treatment with TMP, indicating that TMP can effectively reverse the MDR in BEL-7402/ADM cells, and its activity mechanism may be correlated with the down-regulation of expression in these transporters.
\end{abstract}

Correspondence to: Professor Ji-zhou Xiang, Department of Pharmacology, Tongji Medical College, Huazhong University of Science and Technology, Wuhan City 430030, Hubei Province, P.R. China

E-mail: jizhouxiang2009@163.com

Key words: tetramethylpyrazine, human hepatocellular carcinoma, P-glycoprotein, multidrug resistance-associated proteins

\section{Introduction}

For many anti-neoplastic agents, multidrug resistance (MDR) is a severe problem in human hepatocellular carcinoma (HCC). Many members of the super-family have been reported for their contribution to MDR, some of which are richly expressed in the liver $(1,2)$.

The permeability glycoprotein (P-gp) encoded by MDR1 gene (ABCB1) is a well-known transporter acting as an efflux pump. The overexpression of P-gp can lower intracellular drug accumulation and decrease the cellular toxicity of chemotherapeutics, such as adriamycin, daunorubicin, epirubicin, mitoxantrone, bisantrene, vincristine, vinblastine, etoposide, and paclitaxel (2-4).

Other important ATP-binding cassette transporters located in the liver include multidrug resistance-associated protein 2 (MRP2), MRP 3, and MRP5 encoded by ABCC2, ABCC3 and ABCC5, respectively.

MRP2, a major transporter of bilirubin glucuronides and other organic anions from liver into bile, functions as a pump effluxing cisplatin (different from MRP1), vincristine, anthracyclines, adriamycin, methotrexate (MTX), etoposide, epirubicin, and mitoxantrone $(5,6)$. MRP3, located in the basolateral membrane of the hepatocyte, may allow efflux of organic anions from the liver into the blood when the secretion into bile is blocked, effluxing etoposide, MTX, and teniposide $(7,8)$. MRP5 can be resistance to thiopurines (e.g. 6-mercaptopurine and thioguanine), but no noticeable resistance to other anticancer drugs tested (e.g. anthracyclines, vinca alkaloids, podophyllotoxins, or MTX). The transfected cells tend to accumulate less 6-mercaptopurine and PMEA [9-(2-phosphonylmethoxyethyl) adenine, i.e. adefovir] and extrude increased amount of 6-thioinosinemonophosphate and PMEA from the cells. MRP5, therefore, appears to be a nucleotide analogue pump $(9,10)$.

Tetramethylpyrazine (i.e. ligustrazine, TMP) is a bioactive constituent isolated from the root of Ligusticum chuanxiong Hort, a Chinese herb (Chuanxiong), which is often used as an antioxidant in cardiovascular diseases $(11,12)$. Previous studies showed that such a calcium channel blocker can enhance the chemosensitivity effects of drug on human 
hepatocellular carcinoma BEL-7402 cells, acting as an MDR modulator $(13,14)$. However, it is still unknown if it has effect on other transporters. In this study, the reversal effect of TMP on MDR in multidrug resistant human hepatocellular carcinoma BEL-7402/ADM was investigated and relationships among TMP and MDR1, MRP2, MRP3 and MRP5 were explored.

\section{Materials and methods}

Cell lines and cell culture. The parental human hepatocellular carcinoma cells BEL-7402 and ADM-selected drug-resistant cells BEL-7402/ADM were cultured in our laboratory. All cells were grown in RPMI-1640 medium supplemented with $10 \%$ fetal bovine serum (FBS) at $37^{\circ} \mathrm{C}$ in humidified atmosphere of $5 \% \mathrm{CO}_{2}$ and $95 \%$ air. BEL-7402/ADM were cultured in the above-mentioned medium with the addition of 2,000 nM ADM until at least 2 weeks before the experiment.

Drug and agents. TMP was purchased from Changchun Guoao Pharmaceutical Company (China), verapamil (VRP) was purchased from Shanghai Hefeng Pharmaceutical Company (China), adriamycin (ADM) from Zhejiang Haizheng Pharmaceutical Co., Ltd. (China), P-gp and B-actin monoclonal antibodies from Sigma-Aldrich Chemical Company (USA), while multidrug resistance-associated protein 2 (MRP2), multidrug resistance-associated protein 3 (MRP3) and multidrug resistance-associated protein 5 (MRP5) monoclonal antibodies from Santa Cruz Biotechnology, Inc. (USA). Trypsin, RPMI-1640 and Trizol Reagent were purchased from Gibco Invitrogen (USA), FBS and phosphate buffer solution (PBS) was purchased from Hangzhou Sijiqing Company (China), HRP-conjugated goat anti-mouse IgG from Beijing Biosynthesis Biotechnology Co., Ltd. (China).

Measurement of resistance and reversal by methylthiazoletetrazolium (MTT) assay. To assess cell resistance and drug reversal effect, a measurement of cells proliferation by methylthiazoletetrazolium (MTT) assay was conducted as described previously (15). BEL-7402/ADM cells were preconditioned with TMP (400 and $600 \mu \mathrm{M}$ ) or VRP (5 and $10 \mu \mathrm{M}$ ) for $24 \mathrm{~h}$, respectively, then treated with $0.3,0.6,1.2$, $2.4,4.8 \mu \mathrm{M}$ of ADM in 96-well plate for $72 \mathrm{~h}$, respectively. Verapamil was conducted as positive control. Then the medium was discarded and the cells were washed with PBS. After $30 \mu \mathrm{l}$ MTT solution was added for $2 \mathrm{~h}, 100 \mu 1$ dimethyl sulphoxide (DMSO) was used to dissolve formazan crystals. The absorbance at $540 \mathrm{~nm}$ was recorded. Negative control (without drug) was set as $100 \%$ of cell survival. $\mathrm{IC}_{50}$ value, resistance index and reversal index were calculated as described previously. The resistance index (RI) is calculated as $\mathrm{RI}=(\mathrm{IC}$ Resistance group $) /(\mathrm{IC}$ Parental group $) \times 100 \%$. The reversal index is calculated as RI = (IC Resistance group $) /$ (IC TMP/VRP group) x100\% (16).

Intracellular accumulation of adriamycin (ADM) by flow cytometry (FCM). To assess the steady accumulation of ADM, with/without TMP or VRP as a precondition for $3 \mathrm{~h}, \mathrm{BEL}-7402$ cells and BEL-7402/ADM were incubated with 8,000 nM $\mathrm{ADM}$ for $2 \mathrm{~h}$ at $37^{\circ} \mathrm{C}$, washed 3 times with ice-cold PBS.
Table I. Primer sequences.

\begin{tabular}{llc}
\hline Primers & \multicolumn{1}{c}{ Sequences of primers (5'-3') } & Size (bp) \\
\hline MDR1 & CAT TGG TGT GGT GAG TCA GG & 176 \\
& CTC TCT CTC CAA CCA GGG TG & \\
MRP2 & CGA TAC TCT GTG GCA CTT TCC & 277 \\
& TCA TCA ACT TCC CAG ACA TCC & \\
MRP3 & TGT ATG TGG GTC AAA GTG CG & 108 \\
& CCA GCC TCA GGG AAG TGT T & \\
MRP5 & ACT CGA CCG TTG GAA TGC C & 179 \\
& GGG TGC TGG TGT TTG GAA GT & \\
B-actin & GTT GCG TTA CAC CCT TTC TTG & 155 \\
& CTG CTG TCA CCT TCA CCG TT & \\
\hline
\end{tabular}

The fluorescence intensity of intracellular ADM was recorded by FCM with an excitation wavelength ( $\lambda$ ex) of $480 \mathrm{~nm}$ and emission wavelength $(\lambda \mathrm{em})$ of $575 \mathrm{~nm}(17,18)$.

Intracellular accumulation of ADM by high performance liquid chromatography (HPLC). The accumulation of ADM in cells was also quantified by the HPLC method according to Cox et al with a minor modification (19). Internal standard solution $(50 \mu \mathrm{l})$ (alprazolam, $4 \mu \mathrm{g} / \mathrm{ml})$ was added to $1,000 \mu \mathrm{l}$ samples, after the mix for $2 \mathrm{sec}$, then centrifuged at 4,000 rpm, $2.8 \mathrm{ml}$ supernatant was evaporated at $45^{\circ} \mathrm{C}$ for 2 min under a gentle stream of nitrogen. The resulted residue was reconstituted in $100 \mu 1$ mobile phase, $50 \mu 1$ of the standard/ sample was injected onto the high performance liquid chromatography. HPLC was performed using a Shimadzu LC20AD HPLC system consisted of a UV/VIS detector (SDP20AV), an autosampler (SIL-20A) and an analytical column (Gimini C18, 4.6x250 mm, ID $5 \mu \mathrm{m}$ ). The mobile phase consisted of acetonitrile-water with $\mathrm{KH}_{2} \mathrm{PO}_{4}$ (pH 3.0 adjusted with $\left.\mathrm{H}_{3} \mathrm{PO}_{4}\right)(75: 25, \mathrm{v} / \mathrm{v})$, with a flow rate of $0.8 \mathrm{ml} \cdot \mathrm{min}^{-1}$. The wavelength of ADM detected was $233 \mathrm{~nm}(20,21)$.

Expression levels of MDR1, MRP2, MRP3 and MRP5 mRNA by real-time reverse-transcription- $P C R$ analysis. Total RNA was isolated from BEL-7402 and BEL-7402/ADM in RNA clean solution by Trizole Reagent according to the manufacturer's protocol. All primer pairs (Table I), and their appropriate fluorescent hybridization probes, were designed and produced by Shanghai Sangon Biological Engineering Technology and Services Co., Ltd., China. The mRNA levels of MDR1, MRP2, MRP3 and MRP5 were measured by realtime RT-PCR and quantitated by SLAN real-time PCR detection system (Shanghai Hongshi Medical Science Co., Ltd., China). In addition, the mRNA level of the internal control gene $B$-actin was measured and used to normalize the mRNA levels of the drug resistance genes. The relative expression levels of the resistance genes were calculated using the comparative $\mathrm{Ct}$ value as descirbed previously, and relative amount of target is $2^{-\Delta \Delta C t}$ value. The $\Delta \Delta \mathrm{Ct}$ value in this formula is defined as the $\Delta \mathrm{Ct}$ value of the target gene for 


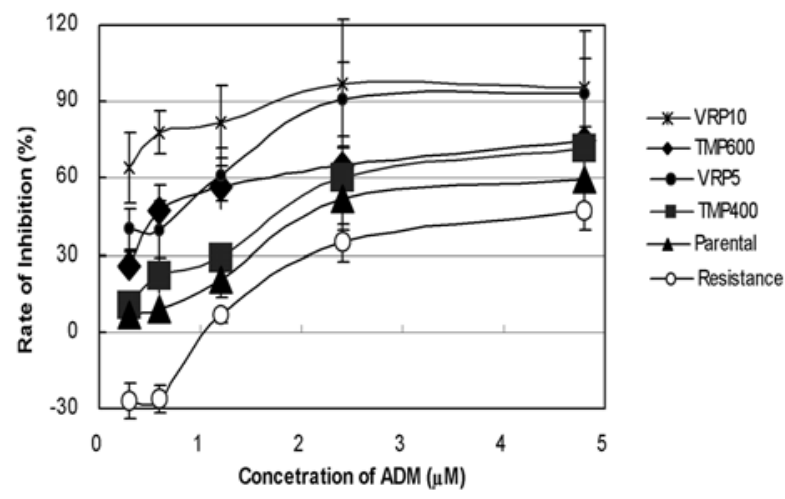

Figure 1. The inhibitory effect of ADM on BEL-7402/ADM cells and BEL7402 cells preconditioned by TMP. A range from 0.3 to $4.8 \mu \mathrm{M}$ of ADM was added into BEL-7402/ADM cells with TMP (400 and $600 \mu \mathrm{M}$ ) or VRP (5 and $10 \mu \mathrm{M}$ ) for $72 \mathrm{~h}$. VRP was conducted as a positive control. Proliferation of cells was measured using the MTT assay, and the inhibition rate $(\%)$ was calculated. Data are expressed as mean $\pm \operatorname{SD}(n=3)$.

Table II. Reversal effect of TMP on BEL-7402/ADM cells.

\begin{tabular}{llcr}
\hline Group & $\mathrm{IC}_{50}$ value & Resistant index & Reversal index \\
\hline Parental & $3.13 \pm 0.56^{\mathrm{a}}$ & & \\
Resistance & $4.8 \pm 0.85$ & 1.53 & \\
TMP400 & $2.01 \pm 0.15^{\mathrm{a}}$ & & 1.59 \\
VRP5 & $0.96 \pm 0.45^{\mathrm{a}}$ & 5.00 \\
TMP600 & $0.52 \pm 0.16^{\mathrm{a}, \mathrm{b}, \mathrm{c}}$ & 9.23 \\
VRP10 & $0.18 \pm 0.04^{\mathrm{a}}$ & 120.00 \\
\hline
\end{tabular}

Data presented are mean $\pm \mathrm{SD}$ value, $\mathrm{n}=3 .{ }^{\mathrm{a}} \mathrm{P}<0.01$ vs. Resistance; ${ }^{\mathrm{b}} \mathrm{P}>0.05$ vs. VRP5; ${ }^{\mathrm{P}}<0.01$ vs. VRP10.

a particular sample subtract the $\Delta \mathrm{Ct}$ value of that target gene of $\beta$-actin $[\Delta \Delta \mathrm{Ct}=\Delta \mathrm{Ct}$ (target) $-\Delta \mathrm{Ct}$ (B-actin) $(22-24)$.

Expressions of MDR1, MRP2, MRP3 and MRP5 proteins by Western blot analysis (WB). BEL-7402 and BEL-7402/ADM cells were harvested, the total protein concentration was determined using bovine serum albumin as a standard. An aliquot of protein $(150 \mu \mathrm{g}$ or $10 \mu \mathrm{g})$ was loaded in each lane to detect the expressions of P-gp, MRP2, MRP3 and MRP5, electrophoresed on 7.5\% SDS-polyacrylamide gel, and transferred to a $0.2 \mu \mathrm{m}$ pore nitrocellulose (NC) membrane (Beyotime Institute of Biotechnology, China). For immunoblotting, the membranes were blocked with $5 \%$ defatted powdered milk in $20 \mu \mathrm{M}$ Tris- $\mathrm{HCl}, 135 \mathrm{mM} \mathrm{NaCl}, 0.1 \%$ Tween-20 buffer at $4^{\circ} \mathrm{C}$ for $2 \mathrm{~h}$. The blots were incubated with the monoclonal antibodies for $2 \mathrm{~h}$, then with peroxidaseconjugated sheep affinity-purified antibody to mouse Ig $\mathrm{G}$ as a secondary antibody for $40 \mathrm{~min}$, and washed for 5 times with $0.1 \%$ Tris buffered saline Tween-20 (TBS-T). All washing and incubation steps were performed at ambient temperature. Proteins were detected and $B$-actin as a reference. Blots were then exposed to a computer scanner and detected by ImageJ 1.38x (NIH, USA).

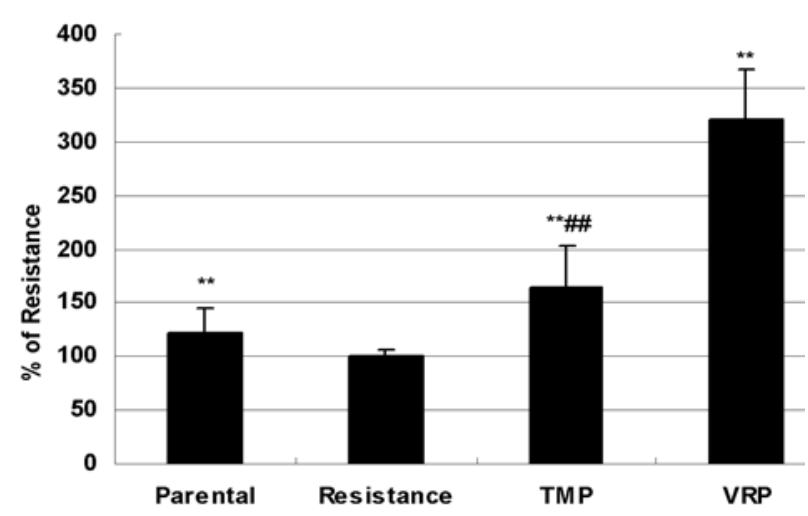

Figure 2. Intracellular accumulation of ADM by FCM. BEL-7402 (Parental group) and BEL-7402/ADM cells (Resistance group) were treated with ADM, all the samples were preconditioned with TMP $(600 \mu \mathrm{M})$ or VRP $(10 \mu \mathrm{M})$ for $24 \mathrm{~h}$, then treated with ADM $8,000 \mathrm{nM}$ for $3 \mathrm{~h}$. Data are expressed as mean $\pm \mathrm{SD}(\mathrm{n}=3)$. ${ }^{* *} \mathrm{P}<0.01$ vs. Resistance; ${ }^{\#} \mathrm{P}<0.01$ vs. VRP.

Statistical analysis. All experiments were performed at least 3 times. Results are presented as the mean \pm SD. Statistical analysis was calculated using the Student's t-test or one-way analysis of variance (oneway ANOVA). P $<0.05$ was considered significant.

\section{Results}

Resistance and reversal results by MTT. Results from the experiment showed that the $\mathrm{IC}_{50}$ value of $\mathrm{ADM}$ for BEL-7402/ ADM cells was $1.53(\mathrm{P}<0.01)$ times than that of ADM for BEL-7402 cells. The reversal was 1.59 -fold $(\mathrm{P}<0.01)$ by TMP at the concentration of $400 \mu \mathrm{M}$ and 9.23-fold $(\mathrm{P}<0.01)$ at the concentration of $600 \mu \mathrm{M}$, respectively, similar to VRP, indicating that the reversal effects of regulators took place in a dose-dependent manner (Fig. 1 and Table II).

Intracellular accumulation of ADM by FCM. The mean fluorescence intensity of ADM in the Parental group, Resistance +TMP group and Resistance +VRP group were $121.83 \pm 23.2 \%(\mathrm{P}<0.01), 163.78 \pm 39.5 \%(\mathrm{P}<0.01)$ and $320.1 \pm 47.18 \%(\mathrm{P}<0.01)$ versus Resistance group by flow cytometry, respectively (Fig. 2).

Intracellular accumulation of ADM by HPLC. The peak area ratio of ADM and internal standard alprazolam was obtained and calculated by HPLC. The calibration curve was obtained as follows with the content ranging from $10 \mathrm{ng} \cdot \mathrm{ml}^{-1}$ to 2,000 $\mathrm{ng} \cdot \mathrm{ml}^{-1}$. The limit of detection (LOD) was $5 \mathrm{ng} \cdot \mathrm{ml}^{-1}$, and RSD was 0.407 .

\section{$\mathrm{C}=47.73 \mathrm{~A}+23.62$ (correlation factor: 0.9998$)$}

Where $\mathrm{C}$ refers to the concentration of ADM, A refers to the peak area ratio of ADM and alprazolam. The mean concentration of ADM in the Parental group, Resistance group, Resistance +TMP group and Resistance +VRP group were 1,421.356, 909.32, 1,152.37, and 1,194.13, respectively. Compared with the ADM level of the Resistance group, that of Parental group, Resistance +TMP group and Resistance 


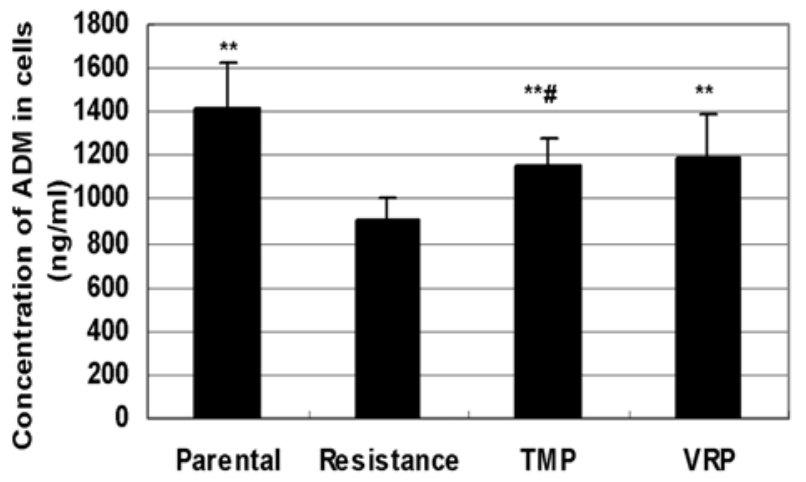

Figure 3. Intracellular accumulation of ADM by high performance liquid chromatography (HPLC). The mobile phase consisted of acetonitrile-water with $\mathrm{KH}_{2} \mathrm{PO}_{4}\left(\mathrm{pH} 3.0\right.$ adjusted with $\left.\mathrm{H}_{3} \mathrm{PO}_{4}\right)(75: 25$, v/v). The injection volume was $50 \mu 1$ and the flow rate was $0.8 \mathrm{ml} \cdot \mathrm{min}^{-1}$. The wavelength for detection of ADM was $233 \mathrm{~nm}$, alprazolam was used as an internal standard. The calibration curve was $\mathrm{C}=47.73 \mathrm{~A}+23.62(\mathrm{r}=0.999$ 8) with the content range of $10 \mathrm{ng} \cdot \mathrm{ml}^{-1}$ to $2,000 \mathrm{ng} \cdot \mathrm{ml}^{-1}$. The experiments were performed 3 times. Data presented are mean $\pm \mathrm{SD}$ value. ${ }^{* *} \mathrm{P}<0.01$ vs. Resistance; ${ }^{*} \mathrm{P}<0.05$ vs. VRP.

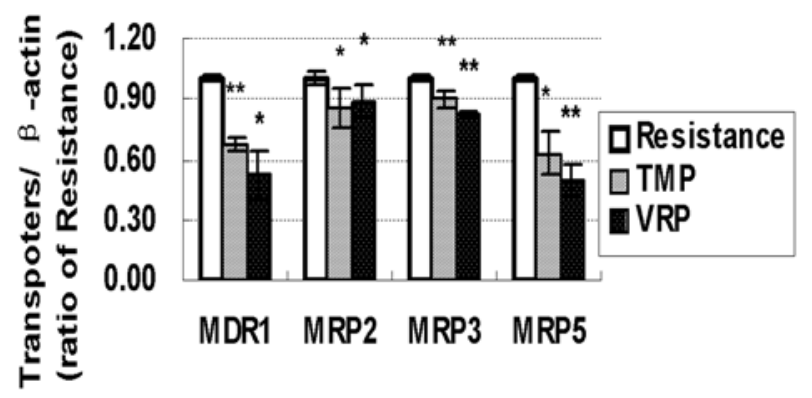

Figure 4. mRNA expression of transporters in BEL-7402/ADM cells. The data presented are the mean \pm SD from at least 3 independent experiments. ${ }^{*} \mathrm{P}<0.05$ vs. Resistance; ${ }^{* *} \mathrm{P}<0.01$ vs. Resistance.

$+\mathrm{VRP}$ group are $156.31 \pm 25.12 \%(\mathrm{P}<0.01), 126.73 \pm 28.72 \%$ $(\mathrm{P}<0.01)$ and $131.32 \pm 47.34 \%(\mathrm{P}<0.01)$, respectively (Fig. 3).

Expressions of MDR1, MRP2, MRP3 and MRP5 mRNA by real-time PCR. The expressions of MDR1, MRP2, MRP3 and MRP5 mRNA in resistant BEL-7402/ADM increased 78 times than that in parental BEL-7402 (Data not shown). Both TMP and VRP can reverse this phenotype remarkably $(\mathrm{P}<0.05)$ (Fig. 4).

Expressions of MDR1, MRP2, MRP3 and MRP5 proteins by $W B$. After treated with TMP or VRP in BEL-7402/ADM cells, Western blot results indicated that expressions of MDR1, MRP2, MRP3, and MRP5 proteins decreased significantly compared with the Resistance group $(\mathrm{P}<0.05)$, in line with their mRNA counterparts (Fig. 5) (22).

\section{Discussion}

A great number of factors is documented to be associated with human carcinomas $(1,25,26)$. MDR is a severe problem to be addressed in resistant HCC. Many membrane

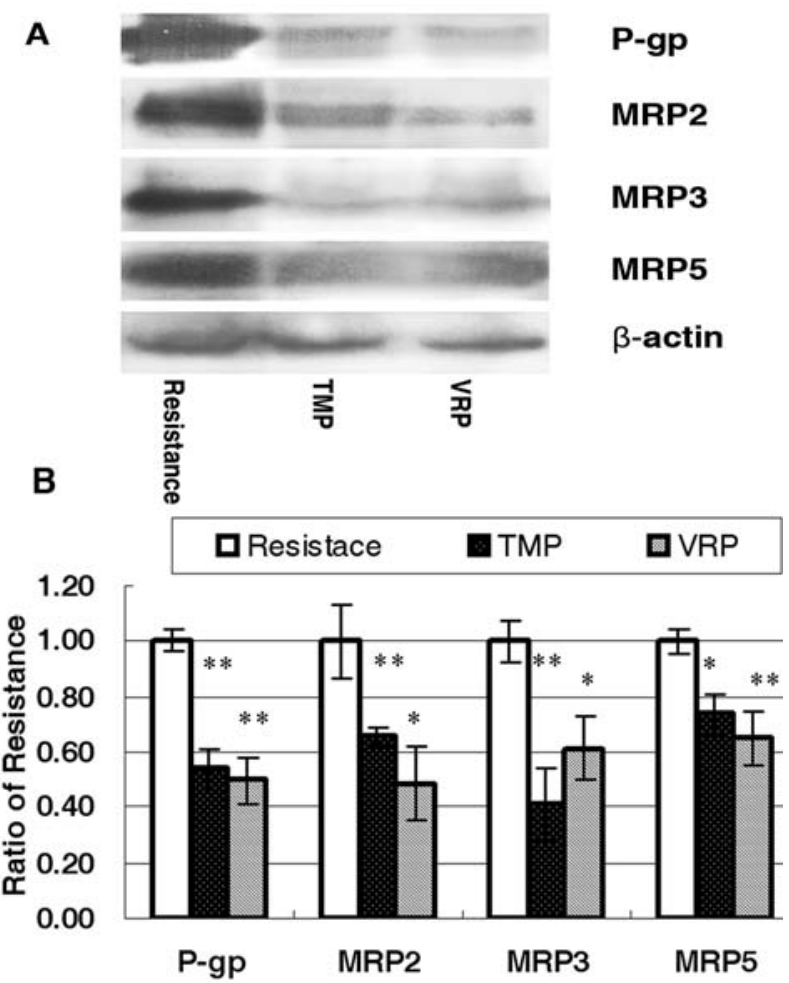

Figure 5. Expressions of MDR1, MRP2, MRP3 and MRP5 proteins in BEL-7402/ADM cells by WB. BEL-7402/ADM cells were treated with TMP or VRP (positive control) for $24 \mathrm{~h}$. Proteins were extracted and subjected to Western blotting to determine P-gp, MRP2, MRP3 and MRP5 expression. Data presented are means $\pm \mathrm{SD}$ values, $\mathrm{n}=3 .{ }^{* *} \mathrm{P}<0.01$ vs. Resistance.

transporters are reported to lead to MDR, some of which share the characteristic of being richly expressed in the liver.

P-gp encoded by MDR1 gene (ABCB1) is a classical transporter acting as an efflux pump. The overexpression of $\mathrm{P}$-gp can decrease intracellular drug accumulation and reduce the cellular toxicity of chemotherapeutics $(1,27-29)$. The other ATP-binding cassette transporters in liver are multidrug resistance-associated proteins (MRP2, MRP3, MRP5) encoded by ABCCs. MRP2 is a major transporter of bilirubin glucuronides and other organic anions from liver into bile. MRP3 may efflux organic anions from the liver into the blood when obstable of secreting into bile occurs. MRP5 can be resistant to thiopurines (e.g., 6-mercaptopurine and thioguanine), but is not notable resistant to other anticancer drugs tested (e.g., anthracyclines, vinca alkaloids, podophyllotoxins, or MTX).

It is unclear if all the proteins mentioned above are reversed together by the same kind of agent. Tetramethylpyrazine (TMP) is a bioactive constituent isolated from the root of a Chinese herb, Chuanxiong. Recent studies have shown that Chuanxiong can enhance the chemosensitivity effects of drug on resistant $\mathrm{HCC}$, acting as an MDR modulator to limit the influx of P-gp substrate into the cells. However, it is still unknown if it has any effect on other transporters. In this study, the reversal experiments of TMP on MDR in multidrug-resistant human hepatocellular carcinoma BEL-7402/ADM were conducted and investigated, and it was found that MDR1, MRP2, MRP3 and MRP5 are 
highly expressed in resistant liver cancer cells and play an important role and jointly contribute to resistance (24) and can be reversed by TMP dose-dependently.

We also found that TMP and another calcium channel blocker, VRP (30) play a similar role on MDR1 $(31,32)$, MRP2, MRP3 and MRP5, and concluded that calcium may play an important role in MDR of MDR1, MRP2, MRP3 and MRP5 which can be reversed by certain calcium channel blockers that deserves further study.

The concentration of TMP $(600 \mu \mathrm{M})$ in this study is too high to be used in human beings, but it might offer a novel way for finding new chemosensitizers from natural products. In conclusion, this study shows that MDR1, MRP2, MRP3, and MRP5 are contributing to MDR mechanism in resistant HCC, and can be reversed by TMP dose-dependently.

\section{Acknowledgements}

The project was sponsored by grants from the Natural Science Foundation of Hubei Province (2007ABA211), the Science Foundation of Department of Health of Hubei Province (JX3B50) and the Science Foundation of the Education Department of Hubei Province (D200724009).

\section{References}

1. Filipits M: Mechanisms of cancer: multidrug resistance. Drug Discov Today Dis Mech 1: 229-234, 2004.

2. Gillet JP, Efferth T and Remacle J: Chemotherapy-induced resitance by ATP-binding cassette transporter genes. Biochim Biophys Acta 1775: 237-262, 2007.

3. Ambudkar SV, Kimchi-Sarfaty C, Sauna ZE and Gottesman MM: P-glycoprotein: from genomics to mechanism. Oncogene 22: 7468-7485, 2003.

4. Zhou SF: Structure, function and regulation of P-glycoprotein and its clinical relevance in drug disposition. Xenobiotica 38: 802-832, 2008

5. de Waart DR, Paulusma CC, Kunne C and Oude Elferink RP: Multidrug resistance associated protein 2 mediates transport of prostaglandin E2. Liver Int 26: 362-368, 2006.

6. Dietrich CG, Ottenhoff R, de Waart DR and Oude Elferink RP: Role of MRP2 and GSH in intrahepatic cycling of toxins. Toxicology 167: 73-81, 2001.

7. Young LC, Campling BG, Voskoglou-Nomikos T, Cole SP, Deeley RG and Gerlach JH: Expression of multidrug resistance protein-related genes in lung cancer: correlation with drug response. Clin Cancer Res 5: 673-680, 1999.

8. Vander Borght S, Libbrecht L, Blokzijl H, et al: Diagnostic and pathogenetic implications of the expression of hepatic transporters in focal lesions occurring in normal liver. J Pathol 207: 471-482, 2005.

9. Borst P, Evers R, Kool M and Wijnholds J: A family of drug transporters: the multidrug resistance-associated proteins. J Natl Cancer Inst 92: 1295-1304, 2000.

10. Zhou SF, Wang LL, Di YM, Xue CC, Duan W, Li CG and Li Y: Substrates and inhibitors of human multidrug resistance associated proteins and the implications in drug development. Curr Med Chem 15: 1981-2039, 2008.

11. Liu XH, Li J, Li QX, Ai YX and Zhang L: Protective effects of ligustrazine on cisplatin-induced oxidative stress, apoptosis and nephrotoxicity in rats. Environ Toxicol Pharmacol 26: 49-55, 2008.

12. Tsai CC, Lai TY, Huang WC, Liu IM and Liou SS: Role of cGMP signals in tetramethylpyrazine induced relaxation of the isolated rat aortic strip. Life Sci 77: 1416-1424, 2005.
13. Zhou CG, Shen P and Cheng YY: Quantitative study of the drug efflux kinetics from sensitive and MDR human breast cancer cells. Biochim Biophys Acta 1770: 1011-1020, 2007.

14. Hu YP, Lin J, Wang QD, Yie QX and Zhang TM: Reversal of adriamycin resistance by verapamil and ligustrazini in mouse Ehrlich ascites cancer. Yao Xue Xue Bao 28: 75-78, 1993 (In Chinese).

15. Chan JYW, Siu KPY and Fung KP: Effect of arsenic trioxide on multidrug resistant hepatocellular carcinoma cells. Cancer Lett 236: 250-258, 2006.

16. Wang XB, Ke J, Wang JN, et al: The inhibitory effect of fluorouracil combined with arsenic trioxide on human colorectal cells SW480 by MTT. Yun Yang Yi Xue Yuan Xue Bao 26: 278-280, 2007 (In Chinese).

17. Wu J, Lu YH, Lee A, Pan XG, Yang XJ, Zhao XB and Lee RJ: Reversal of multidrug resistance by transferrin-conjugated liposomes co-encapsulating doxorubicin and verapamil. J Pharm Pharm Sci 10: 350-357, 2007.

18. Kim D, Lee ES, Park K, Kwon IC and Bae YH: Doxorubicin loaded $\mathrm{pH}$-sensitive micelle: antitumoral efficacy against ovarian A2780/DOXR tumor. Pharm Res 25: 2074-2082, 2008.

19. Cox DS, Scott KR, Gao HL and Eddington ND Effect of Pglycoprotein on the pharmacokinetics and tissue distribution of enaminone anticonvulsants: analysis by population and physiological approaches. J Pharmacol Exp Ther 320: 1096-1104, 2002.

20. Deng WJ, Zeng ZL, Liang YJ, Dai CL, Zhang JY and Fu LW: Detecting doxorubicin concentration in KBv200 and KB cell xenografts in nude mice by high-performance liquid chromatography. Ai Zheng 27: 364-368, 2008 (In Chinese).

21. Kakinoki A, Kaneo Y, Ikeda Y, Tanaka T and Fujita K: Synthesis of poly(vinyl alcohol)-doxorubicin conjugates containing cis-aconityl acid-cleavable bond and its isomer dependent doxorubicin release. Biol Pharm Bull 31: 103-110, 2008.

22. Coburger C, Lage H, Molnár J and Hilgeroth A: Impact of novel MDR modulators on human cancer cells: reversal activities and induction studies. Pharm Res 26: 182-188, 2009.

23. Burger H, Foekens JA, Look MP, et al: RNA expression of breast cancer resistance protein, lung resistance-related protein, multidrug resistance-associated proteins 1 and 2 , and multidrug resistance gene 1 in breast cancer: correlation with chemotherapeutic response. Clin Cancer Res 9: 827-836, 2003.

24. Zhang L, Fang CH and Fan YF: Detection of multidrug resistance-associated proteins MRP2, MRP3, and MRP5 mRNA expression in hepatocarcinoma cells using SYBR real-time PCR. Nan Fang Yi Ke Da Xue Xue Bao 28: 219-224, 2008 (In Chinese).

25. Negoro K, Yamano Y and Nakashima D: Cross-resistance of platinum derivatives in $\mathrm{H}-1 \mathrm{R}$, a cisplatin-resistant cell line. Oncol Rep 21: 443-449, 2009.

26. Soulitzis N, Karyotis I, Delakas D and Spandidos DA: Expression analysis of peptide growth factors VEGF, FGF2, TGFB1, EGF and IGF1 in prostate cancer and benign prostatic hyperplasia. Int J Oncol 29: 305-314, 2006.

27. Lage $\mathrm{H}$ and Dietel M: Effect of the breast-cancer resistance protein on atypical multidrug resistance. Lancet Oncol 1: $1169-1176,2000$

28. Fojo $\mathrm{T}$ and Bates $\mathrm{S}$ : Strategies for reversing drug resistance. Oncogene 22: 7512-7523, 2003.

29. Hennessy M and Spiers JP: A primer on the mechanics of P-glycoprotein the multidrug transporter. Pharmacol Res 55: $1-15,2007$.

30. Vaalburg W, Hendrikse NH, Elsinga PH, Bart J and van Waarde A: P-glycoprotein activity and biological response. Toxicol Appl Pharmacol 207: 257-260, 2005.

31. He L and Liu GQ: Effects of various principles from Chinese herbal medicine on rhodamine 123 accumulation in brain capillary endothelial cells. Acta Pharmacol Sin 23: 591-596, 2002.

32. Mayur YC, Jagadeesh S and Thimmaiah KN: Targeting calmodulin in reversing multidrug resistance in cancer cells. Mini Rev Med Chem 6: 1383-1389, 2006. 